\title{
Effect of Single-Session Aerobic Exercise with Varying Intensities on Lipid Peroxidation and Muscle-Damage Markers in Sedentary Males
}

\author{
Daruosh Moflehi ${ }^{1,2}$, Lian-Yee Kok ${ }^{1}$, Tengku-Fadilah T-K ${ }^{1} \&$ Saidon Amri ${ }^{1}$ \\ ${ }^{1}$ Department of Sport Studies, Faculty of Education, Universiti Putra Malaysia, Serdang, Selangor, Malaysia \\ ${ }^{2}$ Faculty of Physical Education and Sport Science, Shahid Bahonar University, Kerman, Iran \\ Correspondence: Lian-Yee Kok, Department of Sport Studies, Faculty of Education, Universiti Putra Malaysia, \\ 43400 UPM Serdang, Selangor, Malaysia. Tel: 60-163-801-906. E-mail: koklianyee@yahoo.com
}

Received: April 16, 2012 Accepted: May 1, 2012 Online Published: May 23, 2012

doi:10.5539/gjhs.v4n4p48 URL: http://dx.doi.org/10.5539/gjhs.v4n4p48

This research was supported by Universiti Putra Malaysia

\begin{abstract}
Objectives: This study was conducted to evaluate the effect of the different intensity levels of single-session aerobic exercise on serum levels of lipid peroxidation and muscle damage markers in sedentary males. Method: Fifty one sedentary healthy males aged $21.76 \pm 1.89$ years were randomly divided into four groups, with one control $(n=10)$ and three treatment groups that attended single-session aerobic exercise with low $(n=14)$, moderate $(n=14)$, and high $(n=13)$ intensities. The serum levels of malondialdehyde (MDA) and creatine kinase (CK) were measured. Results: Data analysis revealed a significant effect by the intensity levels of aerobic exercise on MDA $(P=0.001)$ and $\mathrm{CK}(P=0.003)$ post-test when the participants in the treatment groups were compared with the control. When the intensity of aerobic exercise was increased, the amount of MDA and CK was also found to be increased. Conclusion: Single-session aerobic exercise can increase the amount of MDA and CK, suggesting that low intensity level of aerobic exercise should be utilized for more adaptation, and to prevent lipid peroxidation and muscle damage in sedentary males.
\end{abstract}

Keywords: single-session aerobic exercise, exercise intensity, malondialdehyde, creatine kinase

\section{Introduction}

Physical activity and regular non-exhaustive exercise have beneficial effects in preventing several chronic diseases such as cardiovascular disease, diabetes, cancer, hypertension, obesity, depression, osteoporosis, and premature death (Powers, Nelson, \& Hudson, 2011; Gomez-Cabrera, Domenech, \& Viña, 2008). Physical activity includes muscular force along with oxygen consumption (Kirschvink, Moffarts, \& Lekeux, 2008). However, as muscular force and/or oxygen consumption increase, reactive oxygen species (ROS), which are oxygen centred free radicals, will be produced in skeletal muscles, liver, and heart during exhausting aerobic exercise (Al Ghouleh, Khoo, Knaus, Griendling, Touyz, Thannickal et al., 2011; Bloomer, Falvo, Fry, Schilling, Smith, \& Moore, 2006). This will result in oxidative stress hurting cell tissues in different ways. It has been reported that oxidative stress not only causes direct damage in lipid, protein, and deoxyribonucleic acids (DNA) through free radicals (Alessio, Hagerman, Fulkerson, Ambrose, Rice, \& Wiley, 2000), but also works as an inflammation regulator (Kvietys \& Granger, 2012; Aoi, Naito, Takanami, Kawai, Sakuma, Ichikawa et al., 2004). It has also been reported that oxidative stress and muscle injury response to equally matched anaerobic exercise is minimal and not different between two modes of training (Bloomer et al., 2006).

Generation of free radicals is influenced by differences in energy requirement, oxygen consumption, and mechanical loads on soft tissue during exercise. Moreover, after unaccustomed exercise, exercise-induced muscle damage is common especially if the exercise is exhaustive or includes eccentric muscle actions (Park, 2006; Sorichter, Puschendorf, \& Mair, 1999). In addition, the formation of free radicals results in lipid peroxidation during aerobic exercise which may cause cell and muscle damage. Malondialdehyde (MDA) has mostly been used as an end-product marker of lipid peroxidation (Bailey, Mceneny, Mathieu-Costello, Henry, James, Mccord et al., 2010). MDA levels during exercise are correlated with creatine kinase (CK) which is an indicator of muscle damage (Guzel, Hazar, \& Erbas, 2007). Several studies have indicated that following 
exercise, levels of lipid peroxidation and muscle-damage markers such as MDA and CK increase (Skenderi, Tsironi, Lazaropoulou, Anastasiou, Matalas, Kanavaki et al., 2008; Guzel et al., 2007), but these increases seemed to be evoked only when participants performed at maximal intensity and not at lower intensities (Rahnama, Gaeini, \& Hamedinia, 2007; Bloomer, Goldfarb, Wideman, Mckenzie, \& Consitt, 2005).

Most of the previously mentioned studies (Lamprecht, Hofmann, Greilberger, \& Schwaberger, 2009; Mergener, Martins, Antunes, Da Silva, Lazzaretti, Fontanive et al., 2009; Radovanovic, Bratic, Nurkic, Cvetkovic, Ignjatovic, \& Aleksandrovic, 2009; Rahnama et al., 2007; Nosaka \& Newton, 2002; Nosaka \& Clarkson, 1994) have examined participates through multiple training sessions. Few researches have focused on single-session activities and their effects on the level of lipid peroxidation and muscle damage markers (Mendham, Donges, Liberts, \& Duffield, 2011; Guzel et al., 2007). In single session exercise, the participants had not enough time for adaptation to a variety of factors such as mechanical stresses which may increase mitochondrial activity resulting in the production of MDA and the leakage of $\mathrm{CK}$ in blood circulation and finally muscle damage (Baechle \& Earle, 2008; Feasson et al., 2002; Jackson, 1999). Therefore, the present study was conducted to investigate the effects of single-session aerobic exercise with different intensities, low, moderate, and high on the rate of changes in MDA and CK markers in sedentary males.

\section{Methodology}

\subsection{Subjects}

From a population of 600 students of the Shahid Bahonar University of Kerman in Iran, 51 sedentary male-students $(21.76 \pm 1.89 \mathrm{yr})$ who were healthy, had no history of regular exercise for at least 6 months, did not consume any supplements such as vitamin $\mathrm{A}, \mathrm{C}$, and $\mathrm{E}$ before and during the exercise session, were randomly selected. They were also examined by the state Sport Medicine Center for any cardiovascular or muscle injuries. All participants were asked to avoid performing any strenuous physical activity three days prior to the exercise session. They were informed about the objectives of the study and gave informed consent before starting the experiment. Ethics approved was also obtained from the university.

\subsection{Aerobic Training}

The subjects were randomly divided into a control group $(\mathrm{n}=10)$ and three single-session aerobic training groups tested under low intensity $(\mathrm{n}=14)$, moderate intensity $(\mathrm{n}=14)$ and high intensity $(\mathrm{n}=13)$ conditions during aerobic exercise. After warming up for 10 minutes on a cycle ergometer and performing dynamic stretching activities, the participants in the training groups were subjected to $20 \mathrm{~min}$ of aerobic treadmill running at low $\left(40 \% \mathrm{VO}_{2}\right.$ max), moderate $\left(60 \% \mathrm{VO}_{2} \max \right)$, and/or high $\left(80 \% \mathrm{VO}_{2} \max \right)$ intensities. Functional capacity $\left(\mathrm{VO}_{2} \max \right)$ was estimated continuously via calculations of the heart-rate reserve (HRR) using a polar belt (Polar Electro Oy Profiessorintie 5 FIN-90440 KEMPELE, Finland) to prescribe aerobic exercise intensity (American College of Sport Medicine ACSM). The target heart rates reserves (THRR) of the participants were estimated using the Karvonen formulas (Baechle \& Earle, 2008). The participants were asked to go on the treadmill $(\mathrm{h} / \mathrm{p} / \operatorname{cosmos} 8$ DE 83365 , Germany) with zero slope angle and begin walking by pressing the start button. Based on the Balke modified protocol (1959), after each minute, the speed $(\mathrm{km} / \mathrm{h})$ was increased until the treadmill speed reached the THRR based on the required intensity.

\subsection{Blood Sampling and Analysis}

Blood samples $(5 \mathrm{ml})$ were taken from an antecubital forearm vein pre-test while participants were fasting and post-test after performing aerobic training on the treadmill. Sera were collected by centrifuging the blood samples at $1500 \times \mathrm{g}$ for $10 \mathrm{~min}$, transferred into clean tubes and stored at $-80^{\circ} \mathrm{C}$ for further analysis. The serum level of MDA was measured through a colorimetric method, where MDA in reaction with thiobarbituric acid produced a colourful complex which can be measured at the absorbance value of $532 \mathrm{~nm}$. The serum concentration of MDA was calculated using a standard curve which was prepared using a two-fold serial dilution of $1 \mathrm{ml}$ tetramethoxypropane ranging from 2.5 to $80 \mathrm{nmol} / \mathrm{ml}$. Serum level of creatine kinase (CK) was measured using an assay kit (Parsazmon, Iran) according to the manufacturer's instruction. Briefly, buffer A and B were mixed with a 1:1 ratio to prepare a volume of $500 \mu 1$. Twenty microliters of the serum samples was added to the mixed buffers, and the absorbance value was measured at $340 \mathrm{~nm}$ using an analyzer (Technicon RA-1000-USA) set at $37^{\circ} \mathrm{C}$. The mixture of buffer A and B was used blank for the assay.

\subsection{Statistical Analysis}

Dependent variables were analyzed using a multivariate analysis of covariance (MANCOVA). In this model the pre-test was controlled as a covariate. The Bonferroni comparisons multiple test was used to evaluate significant levels of the effects. Statistical significance for MANCOVA was set at $\mathrm{p} \leq 0.05$. 


\section{Results}

As shown in Table 1, the intensity levels of aerobic exercise significantly affected the post-test MDA level [F (3, $45)=27.210, P=0.001]$. Likewise, MANCOVA analysis indicated that the intensity levels of aerobic exercise has a significant effect on post-test $\mathrm{CK}[\mathrm{F}(3,45)=5.455, P=0.003]$. In order to determine the relationship between the concentrations of MDA and CK markers pre- and post-test, MDA and CK pre-tests scores were considered as covariate factors. The results indicated a high correlation between the MDA pre- and post-test [F $(1,45)=10.931, P=0.002]$, whereas no significant correlation was observed between pre-test MDA and post-test $\mathrm{CK}[\mathrm{F}(1,45)=0.006, P=0.936]$, indicating that the observed difference between MDA and CK post-test were due to the effect of the intensity levels of the exercise.

Table 1. MANCOVA on the effects of intensity levels of aerobic exercise on MDA and CK post-test score

\begin{tabular}{lccccccccc}
\hline \multicolumn{1}{c}{${ }^{1}$ DV } & \multicolumn{2}{c}{ Intensity level } & \multicolumn{3}{c}{ MDA pre-test } & \multicolumn{3}{c}{ CK pre-test } \\
\hline & df & F & Sig. & df & F & Sig & df & F & Sig. \\
\hline MDA post-test & 3 & 27.21 & $0.001^{*}$ & 1 & 10.93 & $0.002^{*}$ & 1 & 1.53 & 0.222 \\
CK post-test & 3 & 5.46 & $0.003^{*}$ & 1 & 0.01 & 0.936 & 1 & 6.87 & $0.012^{*}$ \\
\hline
\end{tabular}

*Significant at $P<0.05 ;{ }^{1}$ Dependent variable

The effect of the intensity levels of aerobic exercise on MDA post-test was assessed using the Bonferroni comparisons multiple tests at a significance level of $\mathrm{P} \leq 0.05$. The results revealed significant differences among the control and each of the three intensity levels, however, no significant differences among the three intensity levels of aerobic exercise were observed (Table 2) and (Figure 1). The highest amount of MDA post-test was detected in the high intensity level $(\mathrm{M}=9.09, \mathrm{SD}=2.08 \mu \mathrm{mol} / \mathrm{L})$ and the lowest in the control $(\mathrm{M}=2.69, \mathrm{SD}=$ $1.32 \mu \mathrm{mol} / \mathrm{L}$ ). Data analysis of the results obtained for CK also revealed a significant difference among the controls and the participants in the moderate and high intensity levels of exercise, whereas, no significant difference among the control group and the low intensity level was detected. No significant difference among the intensity levels was also found (Table 2) and (Figure 2). The highest amount of CK post-test was measured in the high intensity level $(\mathrm{M}=216.38, \mathrm{SD}=85.62 \mathrm{U} / \mathrm{L})$ and the lowest in the control group $(\mathrm{M}=101.60, \mathrm{SD}=$ $43.71 \mathrm{U} / \mathrm{L})$.

Table 2. Evaluation MDA and CK among intensity levels of aerobic exercise using Bonferroni test

\begin{tabular}{lllllll}
\hline DV $^{1}$ & (I)Intensity Levels & & (J)Intensity levels & Mean $^{2}$ & S.E. $^{3}$ & Sig. \\
\hline MDA post-test & Control & vs. & Low & -5.380 & 0.706 & $0.001^{*}$ \\
& Control & vs. & Moderate & -4.926 & 0.717 & $0.001^{*}$ \\
& Control & vs. & High & -5.928 & 0.723 & $0.001^{*}$ \\
& Low & vs. & Moderate & 0.453 & 0.652 & 1.000 \\
& Low & vs. & High & -0.548 & 0.659 & 1.000 \\
& Moderate & vs. & High & -1.002 & 0.652 & 0.789 \\
CK post-test & Control & vs. & Low & -42.606 & 28.072 & 0.816 \\
& Control & vs. & Moderate & -91.723 & 28.539 & $0.015^{*}$ \\
& Control & vs. & High & -103.559 & 28.746 & $0.005^{*}$ \\
& Low & vs. & Moderate & -49.117 & 25.949 & 0.389 \\
& Low & vs. & High & -60.953 & 26.210 & 0.148 \\
& Moderate & vs. & High & -11.836 & 25.938 & 1.000 \\
\hline
\end{tabular}

*Significant at $P<0.05 ;{ }^{1}$ Dependent variable; ${ }^{2}$ Different means; ${ }^{3}$ Standard Error 


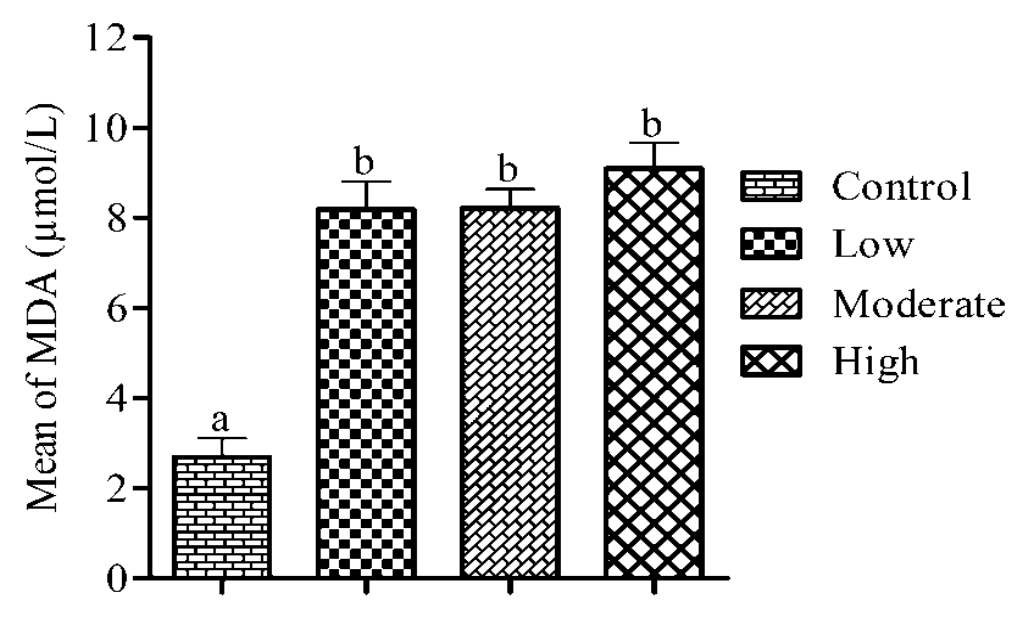

Aerobic intensity levels

Figure 1. The MDA concentration immediately after aerobic exercise with intensity levels

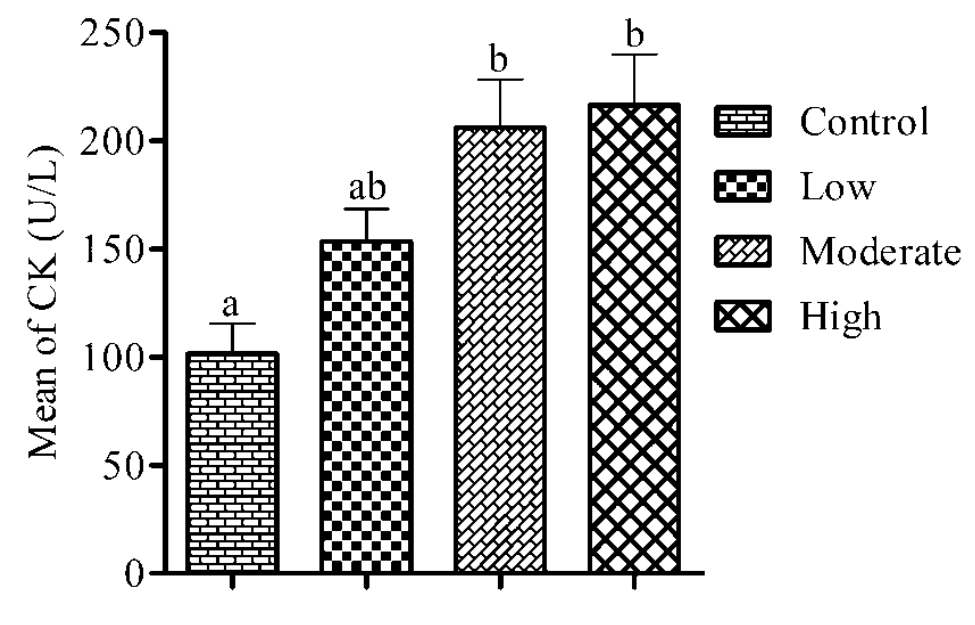

Aerobic intensity levels

Figure 2. The CK concentration immediately after aerobic exercise with intensity levels

\section{Discussion}

Unaccustomed and exhaustive aerobic exercise are thought to cause muscle damage by increasing reaction oxygen species (ROS) production in skeletal muscle, liver, and heart and also play major roles in cardiovascular dysfunction (Park, 2006; Taniyama et al., 2003; Sorichter, Puschendorf, \& Mair, 1999). Production of free radicals during exercises has an important role in lipid peroxidation and muscle damage. There are several possible mechanisms for the production of free radicals during exercise; hyperoxic injury which may occur in highly intense aerobic exercise and high oxygen uptake and $\mathrm{O}_{2}$ flux in an active muscle are important factors in increasing lipid peroxidation and muscle damage, even in highly-trained athletes (Kirschvink et al., 2008; Witt, Reznick, Viguie, Starke-Reed, \& Packer, 1992). High oxygen uptake was shown to increase oxygen flux through the mitochondrial electron transport chain, resulting in a decrease in mitochondrial respiratory control, failure of structural integrity of sarcoplasmic reticulum leading to increased lipid peroxidation and release of myoglobin (Mb) and muscle enzymes into the circulation (Kirschvink et al., 2008; Cannon \& Blumberg, 2000). Peroxidation of lipids, especially polyunsaturated fatty acids in the cell membrane causes a loss in fluidity as well as increases the permeability which can result in loss of cytosolic proteins and enzymes, and a loss of structural sarcoplasmic reticulum. Both of the above conditions may lead to oxidative damage which has been 
suggested to be indicative of an increase in the MDA and CK markers (Baker, Bailey, Hullin, Young, \& Davies, 2004; Cannon \& Blumberg, 2000; Maughan, Donnelly, Gleeson, Whiting, Walker, \& Clough, 1989). Elevation of the serum level of CK may be due to the disruption of the sarcometric Z-disk, resulting in the leakage of this protein out of the cell and into the circulation (Feasson, Stockholm, Freyssenet, Richard, Duguez, Beckmann et al., 2002). Damage to lipid membranes can be caused by oxygen-free radicals produced under certain exercise programs (Sen, Packer, \& Hiinnincn, 2000), even in aerobic exercise of sufficient intensity (Lovlin, Cottle, Pyke, Kavanagh, \& Belcastro, 1987).

The results of this study suggest that lipid peroxidation and muscle damage markers can be affected by the intensity levels of aerobic exercise, where, after a single session of aerobic exercise, significant increases in both MDA and CK was observed. This effect may due to the fact that the participants were sedentary (non-athletes) with no history of regular aerobic exercise, and also did not consume supplements such as antioxidant vitamins (A, C, E) before and during the exercise. Antioxidant supplements can improve antioxidant defences supplied by superoxide dismutase (SOD) against pro-oxidant events (Li, Feng, \& Wang, 2005). Furthermore, the participants did not have enough time for adaptation to a variety of factors including mechanical stresses which may increase mitochondrial activity resulting in the production of MDA and the leakage of CK into the blood circulation, and finally muscle damage (Baechle \& Earle, 2008; Feasson et al., 2002; Jackson, 1999).

These observations are consistent with previously reported results (Lamprecht et al., 2009; Radovanovic et al., 2009; Seifi-Skishahr, Siahkohian, \& Nakhostin-Roohi, 2008; Close, Ashton, Cable, Doran, \& Maclaren, 2004) significant increases in MDA and CK levels after exercise programs. For instance, it was reported that there were significant increases in erythrocyte MDA values after 12 weeks of concurrent training (Radovanovic et al., 2009). Another study (Seifi-Skishahr et al., 2008) showed significant increases in MDA concentrations $2 \mathrm{~h}$ after high-intensity exercise compared with moderate exercise, and higher post-test CK levels $(\mathrm{p}<0.05)$ immediately and $2 \mathrm{~h}$ after exercise in both groups. Significant increases in MDA and CK levels have also been reported following downhill running (Close et al., 2004).

However, there are conflicting reports (Mergener et al., 2009; Rahnama et al., 2007; Close, Ashton, Cable, Doran, Holloway, Mcardle et al., 2006; Bloomer et al., 2005) that detected no significant increases in MDA levels after exercise programs. For example, it was reported that there were no significant increases in MDA levels in groups performing muscle building or walking exercise for $45 \mathrm{~min}$ at least twice a week (Mergener et al., 2009). Another study (Rahnama et al., 2007) utilised aerobic training that included running at $75 \%-80 \%$ of maximal heart rate for 20-45 min per day for eight weeks and found no significant changes in MDA levels at rest and after exercise to exhaustion, although an increase in CK was observed in the experimental group. Bloomer et al. (2005) also could not detect a statistical increase in total plasma MDA at any time point post-exercise following either cycling or squatting. Supporting this further was a study (Nosaka \& Newton, 2002) that reported no significant increase in the CK level following 8 weeks of eccentric training of the elbow flexors at $80 \%$ maximal isometric strength. The divergent results obtained in the different studies may be due to a number of factors such as differences in the duration, intensity, modes of exercise, training status of the participants, age, sex, and even differences in the methods employed for MDA and CK measurement.

\section{Conclusion}

In conclusion, the present study revealed that the intensity levels of aerobic exercise can significantly increase the serum levels of MDA and CK following single-session exercise. The results suggest that by increasing the intensity of exercise, both MDA and CK post-test also increased, indicating that in sedentary people, a single session of high intensity aerobic exercise may increase oxidative stress and lipid peroxidation in skeletal muscle. Therefore, low intensity aerobic exercises can be recommended for sedentary people who want to improve physical fitness without any muscle damage.

\section{Acknowledgement}

We would like to thank the students of Sahid Bahonar University, Kerman, Iran who participated in the experiments. 


\section{References}

Al Ghouleh, I., Khoo, N. K. H., Knaus, U. G., Griendling, K. K., Touyz, R. M., Thannickal, V. J., .. Pagano, P. J. (2011). Oxidases and peroxidases in cardiovascular and lung disease: new concepts in reactive oxygen species signaling. Free Radical Biology and Medicine, 51, 1271-1288. http://dx.doi.org/10.1016/j.freerad biomed.2011.06.011

Alessio, H. M., Hagerman, A. E., Fulkerson, B. K., Ambrose, J., Rice, R. E., \& Wiley, R. L. (2000). Generation of reactive oxygen species after exhaustive aerobic and isometric exercise. Medicine \& Science in Sports \& Exercise, 32(9), 1576-1581. Retrieved from http://www.ncbi.nlm.nih.gov/pubmed/10994907

Aoi, W., Naito, Y., Takanami, Y., Kawai, Y., Sakuma, K., Ichikawa, H., ... Yoshikawa, T. (2004). Oxidative stress and delayed-onset muscle damage after exercise. Free Radical Biology and Medicine, 37(4), 480-487 http://dx.doi.org/10.1016/j.freeradbiomed.2004.05.008

Baechle, T. R., \& Earle, R. W. (2008). Essentials of Strength Training and Conditioning (3rd ed.). Champaign: Human Kinetics.

Bailey, D. M., Mceneny, J., Mathieu-Costello, O., Henry, R. R., James, P. E., Mccord, J. M., ... Richardson, R. S. (2010). Sedentary aging increases resting and exercise-induced intramuscular free radical formation. Journal of Applied Physiology, 109(2), 449-456. http://dx.doi.org/10.1152/japplphysiol.00354.2010

Baker, J. S., Bailey, D. M., Hullin, D., Young, I., \& Davies, B. (2004). Metabolic implications of resistive force selection for oxidative stress and markers of muscle damage during $30 \mathrm{~s}$ of high-intensity exercise. European Journal of Applied Physiology, 92(3), 321-322. http://dx.doi.org/10.1007/s00421-004-1090-9

Bloomer, R. J., Falvo, M. J., Fry, A. C., Schilling, B. K., Smith, W. A., \& Moore, C. A. (2006). Oxidative Stress Response in Trained Men following Repeated Squats or Sprints. Medicine \& Science in Sports \& Exercise, 38(8), 1436-1442. http://dx.doi.org/10.1249/01.mss.0000227408.91474.77

Bloomer, R. J., Goldfarb, A. H., Wideman, L., Mckenzie, M. J., \& Consitt, L. A. (2005). Effects of acute aerobic and anaerobic exercise on blood markers of oxidative stress. J Strength Cond Res, 19(2), 276-285.

Cannon, J. G., \& Blumberg, J. B. (2000). Acute phase immune responses in exercise. Exercise and Oxygen Toxicity, 447-462.

Close, G., Ashton, T., Cable, T., Doran, D., Holloway, C., Mcardle, F., ... MacLaren, Don P. (2006). Ascorbic acid supplementation does not attenuate post-exercise muscle soreness following muscle-damaging exercise but may delay the recovery process. British Journal of Nutrition, 95(05), 976-981. http://dx.doi.org/10.1079/BJN20061732

Close, G. L., Ashton, T., Cable, T., Doran, D., \& Maclaren, D. P. M. (2004). Eccentric exercise, isokinetic muscle torque and delayed onset muscle soreness: the role of reactive oxygen species. European Journal of Applied Physiology, 91(5), 615-621. http://dx.doi.org/10.1007/s00421-003-1012-2

Feasson, L., Stockholm, D., Freyssenet, D., Richard, I., Duguez, S., Beckmann, J., ... Denis, C. (2002). Molecular adaptations of neuromuscular disease-associated proteins in response to eccentric exercise in human skeletal muscle. The Journal of physiology, 543(1), 297-306. http://dx.doi.org/10.1113/jphysiol.2002.018689

Gomez-Cabrera, M. C., Domenech, E., \& Viña, J. (2008). Moderate exercise is an antioxidant: upregulation of antioxidant genes by training. Free Radical Biology and Medicine, 44(2), 126-131. http://dx.doi.org/10.1016/j.freeradbiomed.2007.02.001

Guzel, N., Hazar, S., \& Erbas, D. (2007). Effects of different resistance exercise protocols on nitric oxide, lipid peroxidation and creatine kinase activity in sedentary males. J Sport Sci Med, 6, 417-417.

Jackson, M. J. (1999). Free radical in skin and muscle damaging agents or signals for adaptatin? Proceedings of the National Academy of Sciences, 58(03), 673-676. http://dx.doi.org/10.1017/S0029665199000877

Kirschvink, N., Moffarts, B., \& Lekeux, P. (2008). The oxidant/antioxidant equilibrium in horses. The Veterinary Journal, 177(2), 178-191. http://dx.doi.org/10.1016/j.tvj1.2007.07.033

Kvietys, P. R., \& Granger, D. N. (2012). Role of reactive oxygen and nitrogen species in the vascular responses to inflammation. Free Radical Biology and Medicine, 52, 556-592. http://dx.doi.org/10.1016/j.freeradbiome d.2011.11.002 
Lamprecht, M., Hofmann, P., Greilberger, J. F., \& Schwaberger, G. (2009). Increased lipid peroxidation in trained men after 2 weeks of antioxidant supplementation. International Journal of Sport Nutrition and Exercise Metabolism, 19(4), 385-399.

Li, G., Feng, X., \& Wang, S. (2005). Effects of Cu/Zn Superoxide Dismutase on Strain Injury Induced Oxidative Damage to Skeletal Muscle in Rats. Physiologycal Research, 54, 193-199.

Lovlin, R., Cottle, W., Pyke, I., Kavanagh, M., \& Belcastro, A. N. (1987). Are indices of free radical damage related to exercise intensity. European journal of applied physiology and occupational physiology, 56(3), 313-316.

Maughan, R. J., Donnelly, A. E., Gleeson, M., Whiting, P. H., Walker, K. A., \& Clough, P. J. (1989). Delayed onset muscle damage and lipid peroxidation in man after a downhill run. Muscle \& nerve, 12(4), 332-336. http://dx.doi.org/10.1002/mus.880120412

Mendham, A. E., Donges, C. E., Liberts, E. A., \& Duffield, R. (2011). Effects of mode and intensity on the acute exercise-induced IL-6 and CRP responses in a sedentary, overweight population. European Journal of Applied Physiology, 111(6), 1-11. http://dx.doi.org/10.1007/s00421-010-1724-z

Mergener, M., Martins, M. R., Antunes, M. V., Da Silva, C. C., Lazzaretti, C., Fontanive, T. O., ... Gamaro, G. D. (2009). Oxidative stress and DNA damage in older adults that do exercises regularly. Clinical biochemistry, 42(16-17), 1648-1653. http://dx.doi.org/10.1016/j.clinbiochem.2009.08.001

Nosaka, K., \& Clarkson, P. M. (1994). Effect of eccentric exercise on plasma enzyme activities previously elevated by eccentric exercise. European Journal of Applied Physiology, 69(6), 492-497. http://dx.doi.org/ 10.1007/BF00239865

Nosaka, K., \& Newton, M. (2002). Concentric or eccentric training effect on eccentric exercise-induced muscle damage. Medicine \& Science in Sports \& Exercise, 34(1), 63-69.

Park, K. S. (2006). Exercise-Induce Muscle Damage and Immune Cell Apoptosis. Purdue University West Lafayette, Indiana.

Powers, S. K., Nelson, W. B., \& Hudson, M. B. (2011). Exercise-induced oxidative stress in humans: Cause and consequences. Free Radical Biology and Medicine, 51(5), 942-950. http://dx.doi.org/10.1113/expphysiol. 2009.050526

Radovanovic, D., Bratic, M., Nurkic, M., Cvetkovic, T., Ignjatovic, A., \& Aleksandrovic, M. (2009). Oxidative stress biomarker response to concurrent strength and endurance training. Gen. Physiol. Biophys., 28, 205-211.

Rahnama, N., Gaeini, A. A., \& Hamedinia, M. R. (2007). Oxidative stress responses in physical education students during 8 weeks aerobic training. The Journal of Sports Medicine and Physical Fitness, 47(1), 119-123.

Seifi-Skishahr, F., Siahkohian, M., \& Nakhostin-Roohi, B. (2008). Influence of aerobic exercise at high and moderate intensities on lipid peroxidation in untrained men. The Journal of sports medicine and physical fitness, 48(4), 515-521.

Sen, C. K., Packer, L., \& Hiinnincn, O. (2000). Exercise and Oxygen Radical Production by Muscle. Liverpool: Netherlands.

Skenderi, K. P., Tsironi, M., Lazaropoulou, C., Anastasiou, C. A., Matalas, A. L., Kanavaki, I., ... Chrousos, G. P. (2008). Changes in free radical generation and antioxidant capacity during ultramarathon foot race. European Journal of Clinical Investigation, 38(3), 159-165. http://dx.doi.org/10.1111/j.1365-2362.2007.01 917.x

Sorichter, S., Puschendorf, B., \& Mair, J. (1999). Skeletal muscle injury induced by eccentric muscle action: muscle proteins as markers of muscle fiber injury. Exercise Immunology Review, 5, 5-21.

Taniyama, Y., \& Griendling, K. K. (2003). Reactive oxygen species in the vasculature. Hypertension, 42(6), 1075-1081. http://dx.doi.org/10.1161/01.HYP.0000100443.09293.4F

Witt, E. H., Reznick, A. Z., Viguie, C. A., Starke-Reed, P., \& Packer, L. (1992). Exercise, oxidative damage and effects of antioxidant manipulation. The Journal of Nutrition, 122(3 Suppl), 766-773. 